\title{
Application of Multimedia Assisted Instruction on College English Teaching
}

\author{
Lei Nie $^{1, \text { a }}$ \\ ${ }^{1}$ Jiangxi Science and Technology Normal University, Nanchang, Jiangxi, 330038 \\ a email
}

Keywords: Multimedia Assisted Instruction, Control Charts, Process Capability

\begin{abstract}
With the rapid development of computer technology, computer-aided instruction, especially multimedia technology, is increasingly used in teaching activities in colleges and universities. Although multimedia-assisted English teaching brings some advantages, there are still several misunderstandings at present. Based on the combination of English teaching and multimedia-assisted teaching, this article discusses several major drawbacks of multimedia teaching and puts forward some suggestions on how to make rational use of multimedia-assisted English teaching so as to improve the teaching effect of college English.
\end{abstract}

\section{Introduction}

The multimedia proficiency applied to the course teaching process should always pay attention to teachers and students in the class time assignment. First of all, the role of multimedia should be clarified: filling in the lack of learning materials, making up for video animation and sound effects in ordinary teaching methods, and helping students to understand heavy and difficult issues in order to deepen students' knowledge of knowledge. As the leading position of the teaching process, teachers should grasp their lecturing time and be able to explain the course ideas and tasks clearly and meticulously. The students in the dominant position should give full play to their initiative, make reference to the knowledge material acquired from the multimedia, and actively participate Interactive tutorial. The application of multimedia teaching depends on the actual situation and needs to be supplemented by the curriculum to maximize its usefulness.

Multimedia is popular with most teachers in the classroom for its convenient teaching features, thus replacing some of the traditional teaching methods. Classroom preparation of a multimedia courseware, and can join a variety of learning links, so that students always understand multi-knowledge. However, this does not completely replace the role of traditional teaching methods such as blackboards and blackboards. Through the teaching of the blackboard, the teacher can clearly demonstrate the teaching ideas to the students step by step, but also can flexibly and conveniently change the composition of the blackboard according to the student's reaction so as to achieve full interaction. The teaching materials are also indispensable materials for students to learn. They are selected according to their teaching objectives and are in line with the characteristics of students' learning and learning needs. A large number of knowledge points, learning strategies and problems are set up to assist students to complete their learning tasks. They are the key link between the classroom and students. The teaching method of science should combine the multimedia teaching with the traditional teaching methods, take the traditional teaching methods as the main method and add the multimedia teaching as the auxiliary, and the two work together to achieve the best embodiment of the teaching effect. The general idea can be displayed on the blackboard, and some audio, video or some boring teaching content through multimedia, so that not only allows students to learn clear thinking, but also clearer understanding of heavy and difficult points, to deepen the knowledge of points impression. A correct view of multimedia teaching, this is a teaching tool for teachers teaching but can not be teachers excuse students to give up the original teaching or learning ideas another way. 


\section{Multimedia Courseware Production Precautions}

The amount of knowledge of multimedia courseware should be based on the age characteristics of students, to accept the ability to prepare, students can not exceed the "cognitive fit", that is, due to the large amount of information in multimedia English teaching, high density, rhythmic, teachers in the use of multimedia Teaching must pay attention to courseware capacity within the tolerance of students, otherwise, not only failed to achieve the effect of multimedia teaching and will be counterproductive, so that students have a feeling of irritability. In the course of preparing courseware, in a certain amount of information, marked a heavy difficulty, so that the content of the course structure is simple and understandable. Multimedia English teaching makes the teaching process vivid and interesting. "Activating teaching materials", setting up a new learning environment and using multimedia English correctly can play a multiplier effect. However, it should be clear that high-quality effects are not the result of high frequency use. If multimedia is used as a teaching dependency, all things must be done through multimedia, without grave and difficult levels of division, it will interfere with students, occupy the valuable time of students and students do not get the language knowledge most needed, but without the use and practice This will make it impossible for multimedia to play its due role and will not achieve any practical results.

The primary and secondary marked courseware content, and strive to concise, appropriate use of special effects to enhance teaching effectiveness. A large number of facts show that large-scale text messages can easily make students visually fatigued and their thinking slows down. Special effects of graphic information are used to make students remember or think through different sensory stimuli. If you add them to explain more useful for students to learn. Thus, the effect of learning under multi-sensory stimulation is superior to that of single senses. Therefore, teachers in English teaching, should be added to the appropriate effects, pictures, sounds, etc. and equipped with explanations. In addition, an excellent multimedia courseware is the most basic content is complete and orderly, layers of depth, heavy and difficult to highlight, detailed and appropriate, and then use different effects one by one to show and summarize. But do not introduce a wide variety of special effects and courses have nothing to do with the pictures, animations or backgrounds. Not only reduce the courseware content, but also make students easy to accept, easy to remember. For the layout of courseware, teachers should elaborately design, distinguish the framework structure, to retain students to explore and improvise part of the final Zhang relaxation, according to their own style of teaching habits, rhythmic interaction with the students to complete the teaching task smoothly.

Try to reflect the case-based teaching model. Case-based teaching model, in a similar case of the actual situation, after continuous discussion and research to solve the problem. This process does not attach importance to right and wrong, but emphasizes on the analysis and decision-making ability to exercise; does not pay attention to impart knowledge, and pay attention to the interaction between teachers and students, so that both to improve student participation, but also improve students' interest in learning. Teachers can arrange different cases of tasks for students to actively participate in, through the pre-class preparation, class discussion and analysis, summed up after class, to complete the systematic learning of this knowledge, improvement is only a framework. This will not only ensure teachers sufficient teaching time, but also to mobilize the enthusiasm of students, are interested in participating in the entire learning activities and play an important role. The vivid presentation of the multimedia real case in a scenario or simulation not only benefits students 'understanding and memory, but also completes the teaching objective of students' listening, speaking, reading and writing, which helps students better apply language learning to daily practice This requires teachers to leave more time and interaction opportunities for students during lesson preparation. The case selection should be very careful, it is necessary to consider the acceptability of students but also have a certain degree of difficulty, so that students can think actively when completing the process, be good at brains, learn to contact, enhance the sense of innovation, and ultimately applied to practice . Case-based teaching not only completes the teaching task, but also makes participating students continuously enhance self-confidence and interest in learning. Have to say, multimedia English teaching a wide range of applications and powerful features, so that 
students learn music and learning in the process of learning the language knowledge, but also master the more effective learning methods, adding classroom interaction between teachers and students, making teaching effectiveness Significantly increased.

\section{Multimedia Assisted English Teaching Extracurricular Matters Needing Attention}

Combined with the multi-media network to enhance the deep interaction between teachers and students, the process of "teaching" and "learning" is highly unified. Classroom hours are limited, and it is difficult for teachers to teach classes for the rest of the time to check and guide all students' learning. However, through the multimedia network environment, teachers and students can communicate with each other anytime, anywhere, greatly extending their interaction time. Teachers not only appear in the classroom preach puzzles, but also feel free to contact through the network. Students can also undertake various learning tasks anytime, anywhere and ask the teacher for help. Effective combination of multimedia teaching and network technology not only avoids the unfavorable situation that "teaching" and "learning" are separated, but also strengthens the combination of "teaching" and "learning" to achieve a high degree of unity.

Therefore, according to the characteristics of multimedia assisted teaching, it is necessary to strengthen the training of ability, especially listening and speaking. The introduction of a large number of multimedia audio-visual materials so that students "monasteries," and guide students to some of the classic scene and fragment "reproduction" performance, so that students can greatly improve the ability to hear and listen in English, thinking and presentation skills. In addition to this, you can organize fun and competitive activities such as dividing students into groups or organizing scene dialogues and salons to keep students interested in learning and better learning.

Through the demonstration of multimedia courseware, multimedia-assisted English teaching can vividly display some relatively boring content to students. By stimulating students' senses in many aspects, they are impressed by the pictures, images and dialogues that have appeared. However, if the multimedia courseware too much effect, the picture is too fancy, the sound and light effects too often, the student's attention will be attracted to the multimedia itself and lost focus for the teaching content. This multimedia aids not only failed to improve teaching effectiveness, but has become a hindrance to student learning; the same time, excessive effects will make the classroom more chaotic, so that students know what to do. After completing a "visual feast", students often experience little or no visual fatigue or messy feelings, and even after the hype, they do not even understand the center of gravity and difficulty in the classroom. Such multimedia courseware is undoubtedly the ultimate goal.

Pay attention to the leading role of teacher teaching, the dominant position of student learning and multimedia teaching aids. The role of multimedia is to help students digest and understand teachers' lectures to ensure that students acquire the integrity and systematic knowledge. Therefore, the class teacher must ensure that enough classroom teaching time to ensure that their own ideas in the lecturing process dominated; students also need to play their dominant position in the teaching process, not only passive absorption to adopt, to borrow multimedia The advantages of technology and teacher interaction. For some teaching content, without multimedia assistance can achieve good results, there is no need to use multimedia. Therefore, multimedia teaching methods must be faithful to the actual needs of the classroom, faithful to its own role of teaching aid.

Pay attention to the combination of traditional teaching methods and modern multimedia teaching mode. The emergence of multimedia courseware, it seems, has replaced the blackboard and teaching materials of these traditional teaching methods, it is not. Instead of replacing it with the technical advantages of multimedia, it should be provided as a supplement to classroom teaching. Through the blackboard, teachers can fully control the progress of the classroom and make improvisation, and the blackboard as a carrier of teaching ideas is quite flexible and convenient, can be adjusted at any time. In addition, the board also has a good demonstration. Teachers can demonstrate their students well by themselves; textbooks are the best link between learners and classroom contents. At present, the formal teaching materials that are published are not only the master of teaching contents, but also provide a great deal of learning strategies, methods, 
background introduction and practice and practical application, so the guiding role of student learning is irreplaceable. These features are all modern multimedia teaching methods can not be achieved.

\section{Conclusion}

In the process of teaching, the traditional teaching props should still be the mainstay, meanwhile, the "auxiliary" function of multimedia teaching should be given full play. Classroom teaching ideas should still be reflected on the blackboard, and for some of the unreliable teaching effects on the blackboard and textbooks, such as animation or movie clips, you can express your feelings through multimedia. For some boring focus and difficulty, but also multi-sensory multimedia presentation, in order to deepen the students impression. The role of multimedia should be to help students digest understanding of the contents of the board and teaching materials, rather than another way to give up the teaching of ideas and heavy and difficult to learn.

\section{References}

[1] Deng Cuiying. Talking about the rational application of multimedia-assisted teaching in English classroom [J] .Changjiang Series. 2017 (28)

[2] $\mathrm{Xu}$ An domain. Foreign language teaching in the application of multimedia [J]. Education innovation. 2010 (07)

[3] Chen Qiaozhen. Reasonable use of multimedia, improve junior high school English classroom teaching effectiveness [J]. School of education. 2017 (13)

[4] Xu Shenghua. Use of multimedia-assisted teaching benefits [J]. Test Weekly. 2014 (24)

[5] Chen Yinjuan. Recognize the advantages and disadvantages of multimedia-assisted teaching and its rational and efficient use [J]. Test Weekly. 2014 (A2)

[6] Chen Lu. How to use multimedia-assisted teaching to create a new teaching model of listening class [J]. New curriculum study (on). 2013 (12) 